НЕКОТОРЫЕ АСПЕКТЫ ПРОЦЕССА ДЕФИНИЛИРОВАНИЯ ТРИФЕНИЛВИСМУТА

Залитова Марина Владимировна

Стариий преподаватель Бугульминский филиал

Казанского национального исследовательского технологического университета,

г. Бугульма, Российская Федерация

Семенова Евгения Алексеевна

Сотрудник филиала Бугульминский филиал

Казанского национального исследовательского технологического университета,

г. Бугульма, Российская Федерачия

DOI: 10.31618/ESU.2413-9335.2019.2.60.46-49

\title{
SOME ASPECTS OF THE PROCESS OF DEFINIRANE OF TRIPHENYLBISMUTH
}

\author{
Zalitova Marina Vladimirovna \\ Senior teacher \\ Bugulminskiy branch of Kazan national research technological University \\ Semenova Evgeniya Alekseevna \\ Employee in the branch \\ Bugulminskiy branch of Kazan national research technological University
}

\section{АННОТАЦИЯ.}

Статья посвящена актуальной проблеме современной химии -получение устойчивых арильных соединений висмута и исследование их каталитических свойств. В современных технологических схемах производства в качестве эффективных реагентов и катализаторов используются металлоорганические соединения (MOC), обладающие селективностью и обеспечивающие высокую скорость и более экономически выгодные условия протекания процессов. В связи с этим одной из актуальных проблем химии р-металлов является получение устойчивых арильных соединений висмута и исследование их каталитических свойств.

\section{ABSTRACT.}

The article is devoted to the actual problem of modern chemistry -obtaining stable aryl compounds of bismuth and the study of their catalytic properties. In modern technological schemes of production as effective reagents and catalysts are used organometallic compounds (MOS), which have selectivity and provide high speed and more cost-effective conditions for the processes. In this regard, one of the urgent problems of the chemistry of p-metals is to obtain stable aryl compounds of bismuth and study their catalytic properties.

Ключевые слова: реагент, катализатор, металлоорганическое соединение, синтез, висмут, катализ.

Keywords: reagent, catalyst, organometallic compound, synthesis, bismuth, catalysis.

В современных технологических схемах производства в качестве эффективных реагентов и катализаторов используются металлоорганические соединения (МОС), обладающие селективностью и обеспечивающие высокую скорость и более экономически выгодные условия протекания процессов. Пополнение списка синтезированных металлоорганических соединений, и изучение их свойств, безусловно, имеет важное значение. В связи с этим од- ной из актуальных проблем химии р-металлов является получение устойчивых арильных соединений висмута и исследование их каталитических свойств.

Фенильные соединения висмута проще всего получить по диазометоду Несмеянова. Это метод синтеза висмуторганических соединений разложением двойных солей галоидных производных арилдиазония и фторида бора в присутствии в качестве восстановителя мелко раздробленного висмута.

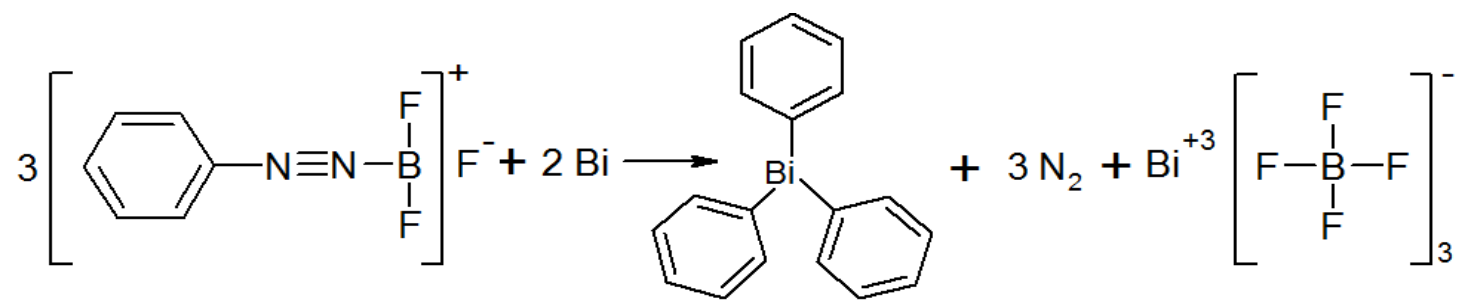

Реакцию проводят при охлаждении в органическом растворителе. В качестве растворителя можно использовать ацетон (максимальный выход 56 \% по массе от теоретически возможного), но в эфире (этилацетат) доля выхода реакции больше при более низких температурах (максимальный выход 78 \% по массе от теоретически возможного). 
В процессе так же идут и конкурирующие реакции галогенирования растворителя и разложения арилдиазониевых солей.

Так же висмуторганические соединения можно получить действием реактива Гриньяра на треххлористый висмут. Этот метод известен с 1904 года и даёт хороший выход в применении к ароматическому ряду, но удобен при получении небольших количеств соединений.

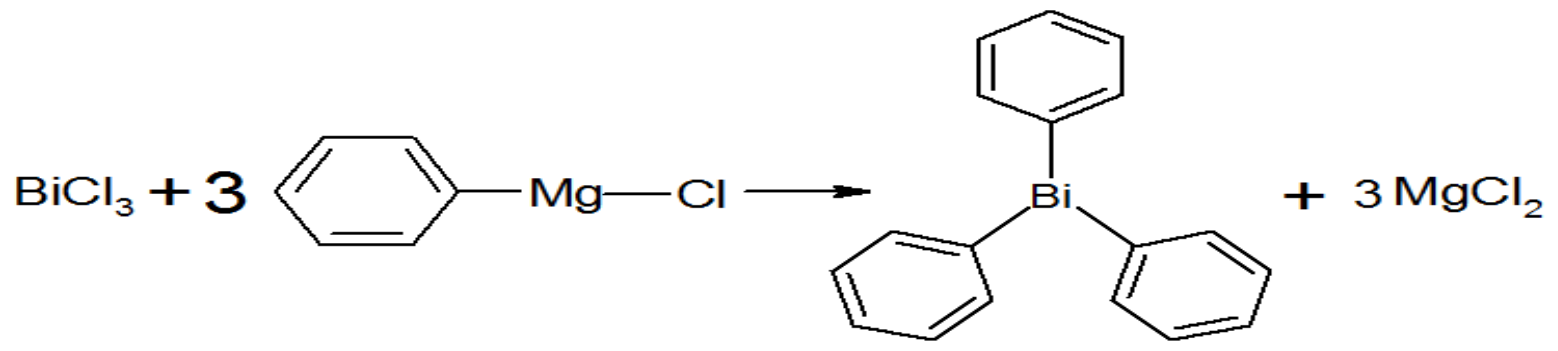

Так же применяются литийорганические соединения, имеющие еще более высокую реакционную способность. Долгое время это был единственный метод получения пентаарильных соединений висмута

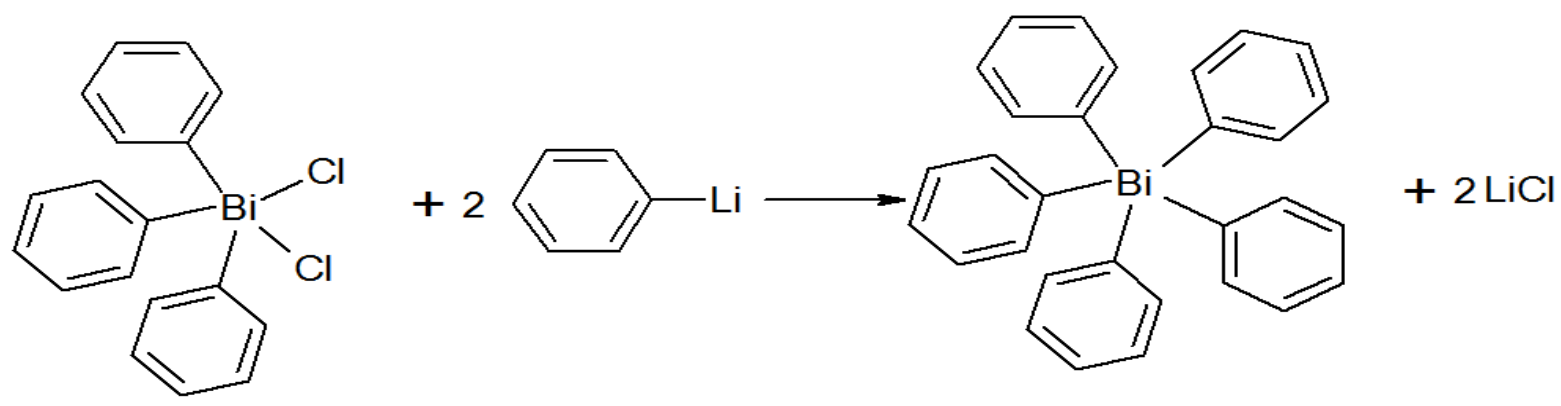

Соединения вида $\mathrm{Ar}_{3} \mathrm{BiX}_{2}$ получают реакцией соответствующего триарилвисмута с галогеном:

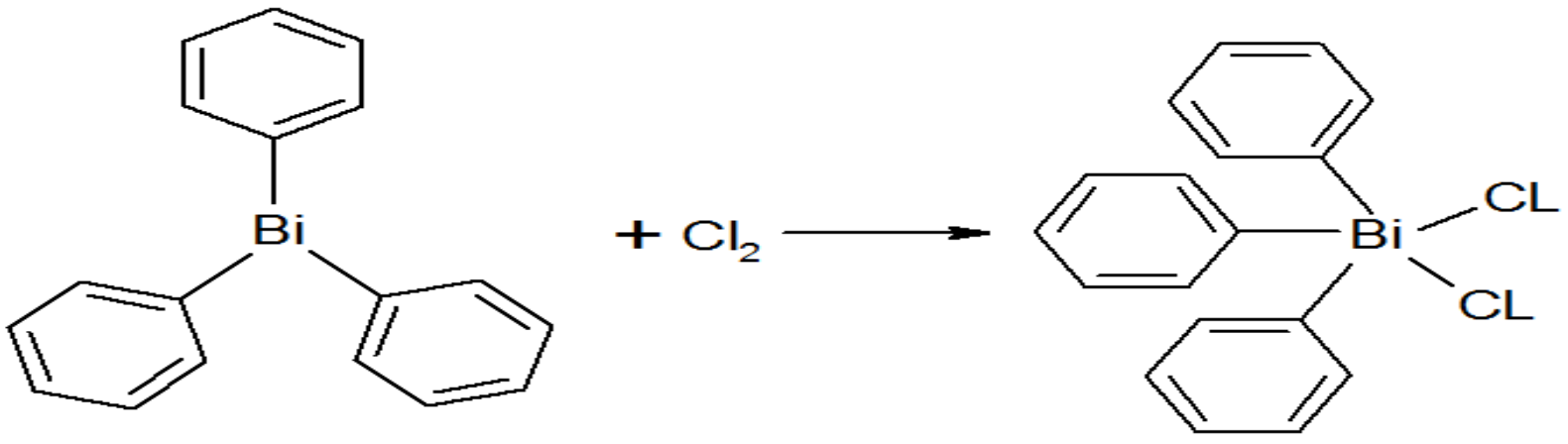

Арильные соединения висмута (III, V) избирательно окисляют, а так же эффективно фенилируют различные органические субстраты. При участии висмуторганических соединений были получены многие аналоги природных алкалоидов, производные индола (серотонин, грамин, резерпин, бруцин), терпеноиды (гингколиды), антибиотики (макролиды), антикоагулянты ( 4-гидроксикумарин). К сожалению, в современном органическом синтезе используется лишь небольшое число самых распространенных висмуторганических катализаторов: трифенилвисмут, пентафенилвисмут, тозилат и трифторацетат тетрафенилвисмута, дихлоротрифенилвисмут. Это объясняется, видимо, тем, что круг синтезированных устойчивых висмуторганических соединений очень узок. Так же отсутствуют подробно описанные методы синтеза данных соединений. Очевидно, что синтез новых органических соединений висмута и изучение их свойств обогатит опыт каталитического синтеза самых разнообразных соединений.

За последнее время были обнаружены и исследованы такие свойства органических производных висмута как комплексов как сверхпроводимость и полупроводимость, а так же явление сегнетоэлектричества в кристаллах висмутсодержащих комплексов. Разработка методов синтеза подобных соединений с точно известным строением ионов, однозначно, даст возможность расширить круг исследовательских направлений в этих областях науки.

Висмутсодержащие комплексы так же представляют интерес и для фундаментальной науки. Особенности строения и свойств данных соединений представляют большой интерес для исследований в области теории химической связи и катализа. 
В последние годы развивается новое направление химии висмутсодержащих комплексов - синтез висмутсодержащих органических веществ с помощью реакций, влияющих на состав и свойства лигандов с последующим их использованием в разных областях синтеза в качестве катализаторов. Развитие данного направления ставит перед современной наукой следующие задачи:

- Разработка эффективных методов получения висмуторганических соединений;

- Подбор методов анализа, устанавливающего и подтверждающего состав и строение синтезированных соединений;

- Изучение фенилирующей эффективности соединений пятивалентного висмута в реакциях с элементоорганическими и неорганическими субстратами.

В последние годы были разработаны новые методы получения соединений висмута с применением реакций переориентации лигандов на основе пентафенилвисмута и висмутсодержащих органических веществ с общей формулой $\mathrm{Ph}_{3} \mathrm{BiR}_{2}$ (где $\mathrm{R}$ это $\mathrm{ReO}_{4}, \mathrm{OAr}, \mathrm{OSO}_{2} \mathrm{C}_{\mathrm{X}} \mathrm{H}_{\mathrm{Y}}$, Hal), так же были разработаны новые способы получения производных висмута общей формулы $\mathrm{Ph}_{4} \mathrm{BiR}$. Эти методы лежат в основе современного востребованного направления в экспериментальном синтезе арильных соединений сурьмы, мышьяка и висмута. Так же найдены современные способы фенилирования соединений трехвалентного висмута с помощью пентафенилвисмута и пентафенилсурьмы; одновременного окисления и фенилирования соединениями с общей формулы $\mathrm{Ph}_{3} \mathrm{BiX}_{2}$ (где $\mathrm{X}$ это $\mathrm{Br}, \mathrm{NO}_{3}$, и некоторые другие) трифенилсурьмы и трифенилмышьяка с образованием производных сурьмы.

Доказано, что взаимодействие триарилвисмута с фенольными соединениями в присутствии пероксида водорода при мольном соотношении реагентов $(1: 1)$ протекает с образованием соединений висмута общей формулы $\left(\mathrm{Ar}_{3} \mathrm{BiX}\right)_{2} \mathrm{O}$.<smiles>[R]c1ccc([Bi](c2ccc([R])cc2)c2ccc([R])cc2)cc1</smiles><smiles>[R]c1ccc([Bi](c2ccc([R])cc2)c2ccc([R])cc2[Bi](c2ccc([R])cc2)c2ccc([R])cc2)cc1</smiles>

При взаимодействии трифенилвисмута с замещенными толуиловых кислот и бензойных кислот а так же с хлор- и бромуксусной кислотами протекающие в равных эквивалентных соотношениях приводят приимущественно к выделению веществ состава $\mathrm{Ph}_{2} \mathrm{BiX}$.<smiles>Cc1cccc(C(=O)OCc2ccccc2)c1</smiles>

Так же могут заместиться все три фенильных радикала, это зависит от мольного соотношения исходных реагентов (1:1, 1:2 или 1:3), природы растворителя, температуры. По данным последних лет висмутсодержащие карбоксилаты являются димерами или олигомерами, где атомы висмута высококоординированы. 
Таблица 1Выход продуктов в реакции трифенилвисмута с толуиловой кислотой в разных условиях.

\begin{tabular}{|l|l|l|c|}
\hline$№$ & \multicolumn{1}{|c|}{ Соединение } & \multicolumn{1}{|c|}{ Условия } & Выход \\
\hline 1 & $\mathrm{Ph}_{2} \mathrm{BiOC}(\mathrm{O}) \mathrm{C}_{6} \mathrm{H}_{4}\left(\mathrm{CH}_{3}-3\right)$ & $1: 1$, растворитель - толуол, 45 $\mathrm{C}, 20$ мин & $72 \%$ \\
\hline 2 & $\mathrm{PhBi}\left(\mathrm{OC}(\mathrm{O}) \mathrm{C}_{6} \mathrm{H}_{4}\left(\mathrm{CH}_{3}-3\right)\right)_{2}$ & $1: 2$, растворитель - толуол, $45^{0} \mathrm{C}, 30$ мин & $38 \%$ \\
\hline 3 & $\mathrm{PhBi}\left(\mathrm{OC}(\mathrm{O}) \mathrm{C}_{6} \mathrm{H}_{4}\left(\mathrm{CH}_{3}-3\right)\right)_{2}$ & $1: 1$, растворитель - гексан, $18^{0} \mathrm{C}, 7$ мин & $89 \%$ \\
\hline 4 & $\mathrm{PhBi}\left(\mathrm{OC}(\mathrm{O}) \mathrm{C}_{6} \mathrm{H}_{4}\left(\mathrm{CH}_{3}-3\right)\right)_{2}$ & $1: 1$, растворитель - гексан, $18^{0} \mathrm{C}, 30$ мин & $29 \%$ \\
\hline 5 & $\mathrm{Bi}\left(\mathrm{OC}(\mathrm{O}) \mathrm{C}_{6} \mathrm{H}_{4}\left(\mathrm{CH}_{3}-3\right)\right)_{3}$ & $1: 2,1: 3$, растворитель - гексан, $18^{0} \mathrm{C}, 30$ мин & $\begin{array}{l}\text { Образуется гель, } \\
\text { выделить невоз- } \\
\text { можно }\end{array}$ \\
\hline 6 & $\mathrm{PhBi}\left(\mathrm{OC}(\mathrm{O}) \mathrm{C}_{6} \mathrm{H}_{4}\left(\mathrm{CH}_{3}-3\right)\right)_{2}$ & $1: 1$, растворитель - ацетон, $18^{0} \mathrm{C}, 8$ мин & $60 \%$ \\
\hline 7 & ${\mathrm{PhBi}\left(\mathrm{OC}(\mathrm{O}) \mathrm{C}_{6} \mathrm{H}_{4}\left(\mathrm{CH}_{3}-3\right)\right)_{2}}_{8}$ & $1: 1$, растворитель - ацетон, $18^{0} \mathrm{C}, 30$ мин & Более $99 \%$ \\
\hline
\end{tabular}

В реакции трифенилвисмута с хлоруксусной и бромуксусной кислотами участвует кислород, в результате образуются комлексы дикарбоксилатов фенилвисмута. В зависимости от растворителя и режима

Таблица 2 Выход продуктов в реакции трифенилвисмута с бромуксусной и хлоруксусной кислотами кислотой в разных условиях.

\begin{tabular}{|c|c|c|c|}
\hline № & Соединение & Условия & Выход \\
\hline 1 & $\mathrm{PhBi}\left(\mathrm{OC}(\mathrm{O}) \mathrm{CH}_{3} \mathrm{Cl}\right)_{2}$ & $1: 1$, растворитель - толуол, $20^{\circ} \mathrm{C}, 10$ мин & $62 \%$ \\
\hline 2 & $\mathrm{PhBi}\left(\mathrm{OC}(\mathrm{O}) \mathrm{CH}_{3} \mathrm{Cl}\right)_{2}$ & $1: 2$, растворитель - толуол, $20^{\circ} \mathrm{C}, 10$ мин & $56 \%$ \\
\hline 3 & $\mathrm{PhBi}\left(\mathrm{OC}(\mathrm{O}) \mathrm{CH}_{3} \mathrm{Cl}\right)_{2}$ & $1: 1$, растворитель - толуол, $40^{\circ} \mathrm{C}, 10$ мин & $24 \%$ \\
\hline 4 & $\mathrm{PhBi}\left(\mathrm{OC}(\mathrm{O}) \mathrm{CH}_{3} \mathrm{Cl}\right)_{2}$ & $1: 2$, растворитель - толуол, $40^{\circ} \mathrm{C}, 10$ мин & $19 \%$ \\
\hline 5 & $\mathrm{Bi}\left(\mathrm{OC}(\mathrm{O}) \mathrm{CH}_{3} \mathrm{Cl}\right)_{3}$ & $1: 1$, растворитель - толуол, $20^{\circ} \mathrm{C}, 10$ мин & $29 \%$ \\
\hline 6 & $\mathrm{Bi}\left(\mathrm{OC}(\mathrm{O}) \mathrm{CH}_{3} \mathrm{Cl}\right)_{3}$ & $1: 2$, растворитель - толуол, $40^{\circ} \mathrm{C}, 10$ мин & $38 \%$ \\
\hline 7 & $\mathrm{Bi}\left(\mathrm{OC}(\mathrm{O}) \mathrm{CH}_{3} \mathrm{Cl}\right)_{3}$ & $1: 1$, растворитель - толуол, $40^{\circ} \mathrm{C}, 10$ мин & $76 \%$ \\
\hline
\end{tabular}

Таким образом взаимодействие трифенилвисмута с карбоновыми кислотами и их производными в зависимости от соотношения исходных веществ, температуры, состава кислоты и растворителя протекает с образованием трикарбоксилатов висмута а так же дикарбоксилатов фенилвисмута. Если в качестве растворителя применить толуол, в зависимости от мольного соотношения реагентов и условий проведения реакции, возможно образование дикарбоксилата фенилвисмута и трикарбоксилата висмута в разных процентных содержаниях.

\section{Список литературы:}

1. Разуваев Г.А., Осанова Н.А., Шарутин В.В. Исследование реакций пентафенилвисмута II Докл. АН СССР,-1975.- Т. 225, № 3.- С. 581-582.

2. Шарутин В.В., Шарутина О.К., Павлушкина И.И., Егорова И.В., Пакусина А.П., Криволапов Д.Б., Губайдуллин А.Т., Литвинов И.А. Взаи- модействие бис (аренсульфонатов) трифенилвисмута с три-феншстибином II Журн. общ. химии.2001.- Т. 71, вып. 1.- С. 87-90.

3. Павлушкина И.И. Арильные кислородсодержащие соединения висмута. Синтез, строение и некоторые реащни // Дисс. канд. хим. наук.-Иркутск.- 2002.- 116 с.

4. Додонов В. А., Гущин А.В., Брилкина Т.Г. Синтез и некоторые реакциидиацилатов трифенилвисмута И Журн. общ. химии.- 1985.- Т. 55, вып. 1.-С. 73-80.

5. Додонов В.А., Гущин А.В., Гришин Д.Ф., Брилкина Т.Г. Реакции диалкоксидов трифенилвисмута // Журн. общ. химии.- 1984.- Т. 54, вып. 1.- С. 100-103.

6. Троянов С.И., Писаревский А.П. Кристаллическая структура Вi(02СCH3)3 II Коорд. химия.- 1991.- Т. 17, № 7.- С. 909-913. 